\title{
Intervention heroes of Mozambique from 1997 to 2015: estimates of maternal and child lives saved using the Lives Saved Tool
}

Ivalda Macicame ${ }^{1}$, Amílcar Magaço ${ }^{1}$, Marta Cassocera ${ }^{1}$, Celeste Amado ${ }^{2}$, Américo Feriano ${ }^{1}$, Sérgio Chicumbe ${ }^{1}$, Jorge Jone ${ }^{1}$, Quinhas Fernandes ${ }^{2}$, Kátia Ngale $^{3}$, Emilia Vignola ${ }^{3}$, Caroline De Schacht ${ }^{4}$, Timothy Roberton ${ }^{3}$

\footnotetext{
${ }^{1}$ Instituto Nacional de Saúde, Ministry of Health, Maputo, Mozambique

2 Direcçăo Nacional de Saúde Pública, Ministry of Health, Maputo, Mozambique

${ }^{3}$ Johns Hopkins University - Bloomberg

School of Public Health, Baltimore, Maryland, USA

${ }^{4}$ Health Alliance International, Maputo, Mozambique
}

Background: As one of several countries that pledged to achieve the Millennium Development Goals (MDGs), Mozambique sought to reduce child, neonatal, and maternal mortality by two thirds by 2015 . This study examines the impact of Mozambique's efforts between 1997 and 2015, highlighting the increases in intervention coverage that contributed to saving the most lives.

Methods: A retrospective analysis of available household survey data was conducted using the Lives Saved Tool (LiST). Baseline mortality rates, causeof-death distributions, and coverage of child, neonatal, and maternal interventions were entered as inputs. Changes in mortality rates, causes of death, and additional lives saved were calculated as results. Due to limited coverage data for the year 2015, we reported most results for the period 1997-2011. For 2011-2015 we reported additional lives saved for a subset of interventions. All analyses were performed at national and provincial level.

Results: Our modelled estimates show that increases in intervention coverage from 1997 to 2011 saved an additional 422282 child lives (0-59 months), 85450 neonatal lives (0-1 month), and 6528 maternal lives beyond those already being saved at baseline coverage levels in 1997. Malaria remained the leading cause of child mortality from 1997 to 2011; prematurity, asphyxia, and sepsis remained the leading causes of neonatal mortality; and hemorrhage remained the leading cause of maternal mortality. Interventions to reduce acute malnutrition and promote artemisinin-based combination therapy (ACT) for malaria were responsible for the largest number of additional child lives saved in the 1997-2011 period. Increases in coverage of delivery management were responsible for most additional newborn and maternal lives saved in both periods in Mozambique.

Conclusion: Mozambique has made impressive gains in reducing child mortality since 1997. Additional effort is needed to further reduce maternal and neonatal mortality in all provinces. More lives can be saved by continuing to increase coverage of existing health interventions and exploring new ways to reach underserved populations.

\section{Correspondence to:}

Ivalda Macicame

Instituto Nacional de Saúde

Vila de Marracuene

Estrada Nacional N¹, Parcela N³943

Província de Maputo

Moçambique

ivalda.macicame@gmail.com
Like many sub-Saharan African countries, Mozambique made a commitment to achieve Millennium Development Goals (MDGs) 4 and 5: to reduce its under-five mortality rate (U5MR) by two thirds and its maternal mortality ratio (MMR) by three quarters by 2015 [1]. Results from Demographic and Health Surveys (DHS) in 1997, 2003, and 2011 suggest that Mozambique went a long way to achieving the U5MR target, but not the MMR target. The U5MR decreased from 201 in 1997 to 153 in 2003 and 97 in 2011 [2-4]. The MMR declined from 692 in 1997 to 408 in 2003, but then remained stagnant at 408 in 2011 [2-4]. 
In the coming years, the Mozambique Ministry of Health aims to "accelerate progress in reducing maternal and neonatal mortality" to achieve Sustainable Development Goals (SDGs) 3.1 and 3.2, as outlined in its Health Sector Strategic Framework (PESS) for 2014-2019 [5]. To successfully prioritize the scale-up of interventions during this next period, it will help to first explore which interventions were most impactful during the previous period. Understanding how the scale-up of interventions has contributed to saving lives in the past will help to set effective targets and expectations going forward.

The Lives Saved Tool (LiST) is a modelling program within the Spectrum software package that has been used in various settings to model the impact of coverage changes on child and maternal mortality $[6,7]$. Users enter custom input values for baseline mortality rates, cause-of-death distributions, disease incidence, and coverage rates. Outputs can be generated showing how increases in coverage prevent additional deaths over time, affecting mortality rates and causes of death [8]. The number of additional lives saved can be attributed to specific interventions, allowing users to see which interventions contributed the most to reducing deaths and improving population health.

As part of work undertaken with the National Evaluation Platform (NEP) in Mozambique, we conducted a retrospective LiST analysis to estimate the additional lives saved by changes in intervention coverage from 1997 to 2015. The NEP supports effective policy-making for child and maternal health, by conducting secondary analyses of national and provincial data and supplying policy-makers with evidence to inform decisions [9]. Our goal was to highlight the programmatic efforts in Mozambique that were most impactful in reducing child, neonatal, and maternal deaths from 1997 to 2015, so as to inform future efforts to achieve the SDGs and continue to improve the health of women and children throughout the country.

\section{METHODS}

\section{Study design and data sources}

In this retrospective secondary analysis, we modelled national and provincial changes in coverage of child and maternal health interventions between 1997 and 2015, and estimated the impact of those coverage changes on child, neonatal, and maternal mortality in Mozambique. Intervention coverage data were obtained from Demographic Health Surveys (DHS) in 1997, 2003, and 2011; a Multiple Indicator Cluster Survey (MICS) in 2008; an AIDS Indicator Survey (AIS) in 2009; and an Immunization, Malaria and HIV/ AIDS Indicators Survey (IMASIDA) in 2015. These surveys represent all of the available household surveys with data on coverage of child and maternal health interventions in the past 20 years that are representative at national and provincial levels.

For national baseline child and neonatal mortality rates we used estimates from the UN Inter-agency Group for Child Mortality Estimation (UN IGME) [10]. For baseline maternal mortality rates we used published estimates from WHO, UNICEF, UNFPA, World Bank Group, and the UN Population Division [11]. We calculated provincial baseline mortality rates using national-to-subnational LiST projections to estimate provincial mortality rates based on differences in provincial coverage to national coverage.

The data sources for baseline cause-of-death estimates for Mozambique at national level were those used by LiST by default and come from WHO mortality estimates $[12,13]$. For provincial cause-of-death estimates, we created national-to-subnational LiST projections (as above) to estimate provincial cause-ofdeath estimates based on differences in provincial coverage to national coverage.

\section{Data analysis}

Of the 72 indicators with known effectiveness values that are customizable within LiST, we identified 55 indicators available in the Mozambique household survey data sets, including preventative and curative interventions during pregnancy, childbirth, the neonatal period, and childhood. We used raw survey data to recalculate certain indicators using the software STATA version 13 (Stata Corp, College Station, TX: StataCorp LP), so as to standardize indicators for comparison over time, and to match the indicator definitions expected by LiST. Additionally, we calculated proportions of children stunted and wasted by age category and Z-score, to accurately calculate the impact of interventions on children in different risk categories.

We undertook our analysis with LiST version 5.441 (Spectrum). We manually inputted survey coverage data for the years that were available, and linearly interpolated between these years. For indicators that were not available in survey data sets, or for which only one year of data was available, we flatlined cover- 
age from 1997 to 2015 and these interventions thus had no effect on the model. For indicators where data was available for only two years, or was not available for either 1997 or 2015, we linearly interpolated coverage between the available years, and duplicated (flatlined) coverage before and after the available years.

Once the projections were complete, we used LiST to generate three types of outputs at national and provincial levels: mortality rates, number of deaths by cause, and number of additional lives saved by intervention. For each of these outputs we separated results by age category: neonatal (0-1 month), child (059 months), and maternal. Once we had calculated the additional lives saved for each intervention, we identified the 10 interventions that contributed the largest number of additional lives saved nationally, and listed the number and proportion of additional lives saved from the same interventions by province.

While we had data for most indicators for the years 1997, 2003, 2008, 2009, and 2011, we only had data for a limited number of indicators from the 2015 IMASIDA survey. Given that LiST relies on coverage data to calculate accurate results, the limited availability of 2015 data meant that LiST would underestimate the number of lives saved in the period 2011-2015. We therefore chose to present our findings in two time periods: 1997-2011 and 2011-2015. For 1997-2011 we reported all available results. For 2011-2015 we only reported additional lives saved for a subset of interventions.

\section{RESULTS}

\section{Changes in coverage of interventions}

The coverage values for child, neonatal, and maternal interventions that we used as inputs for our LiST projections are available in Table 1 (national coverage values for single-value indicators) and Appendices S1 \& S2 in Online Supplementary Document (breastfeeding, stunting, and wasting by age category; and provincial coverage values). While there were variations in coverage rates over time and across provinces, most interventions showed a general increase in coverage from 1997 onwards. Coverage of vaccines increased in all provinces of Mozambique from 1997 to 2011, and continued to increase in most provinces until 2015. Coverage of diphtheria-tetanus-pertussis vaccine 3 doses (DPT3) decreased in Tete between 2011 and 2015, and coverage of measles vaccine decreased in Nampula from 2011 to 2015. Coverage of oral rehydration solution (ORS) for diarrhea increased nationally from 1997 to 2011, but decreased in many provinces from 2011 to 2015. Coverage of pneumonia interventions increased steadily from 1997 to 2015. Coverage of malaria interventions increased nationally, although Maputo Province and Mapu-

Table 1. Intervention coverages at national level from 1997 to 2015

\begin{tabular}{|c|c|c|c|c|c|c|c|}
\hline & & DHS & DHS & MICS & AIS & DHS & IMASIDA \\
\hline & & 1997 & 2003 & 2008 & 2009 & 2011 & 2015 \\
\hline \multirow{4}{*}{ Preventive } & ITN/IRS & & $5.80 \%$ & $26.17 \%$ & & $51.45 \%$ & \\
\hline & Improved drinking water source & $70.15 \%$ & $83.15 \%$ & $83.23 \%$ & $89.00 \%$ & $84.00 \%$ & \\
\hline & Water channeled into the household & $4.85 \%$ & $5.26 \%$ & $6.85 \%$ & $6.01 \%$ & $10.82 \%$ & \\
\hline & Improved Sanitary Infrastructures & $28.59 \%$ & $39.40 \%$ & $41.04 \%$ & $41.74 \%$ & $49.09 \%$ & \\
\hline \multirow{3}{*}{ Pregnancy } & Antenatal care (ANC) 4 or more visits & $40.77 \%$ & $52.95 \%$ & & & $48.44 \%$ & $54.60 \%$ \\
\hline & Tetanus vaccine: $2+$ doses during the most recent pregnancy & $30.94 \%$ & $58.68 \%$ & $66.75 \%$ & & $66.26 \%$ & \\
\hline & Intermittent and preventive treatment for malaria during pregnancy & & & $44.10 \%$ & $40.74 \%$ & $20.35 \%$ & $34.20 \%$ \\
\hline \multirow{2}{*}{ Delivery } & Skilled birth attendant (births in 2 years before survey) & $44.60 \%$ & $49.89 \%$ & $55.25 \%$ & & $55.99 \%$ & $73.00 \%$ \\
\hline & Facility delivery & $44.33 \%$ & $50.91 \%$ & $58.09 \%$ & & $58.86 \%$ & $70.30 \%$ \\
\hline \multirow{2}{*}{ Preventive } & Vitamin A in the last 6 months (6-59 months of age) & & $52.00 \%$ & $71.99 \%$ & & $75.19 \%$ & \\
\hline & Safe excretion of the child's stool & & $57.49 \%$ & $56.93 \%$ & & $77.84 \%$ & \\
\hline \multirow{2}{*}{ Vaccine } & Received 3 doses of DPT & $60.27 \%$ & $72.73 \%$ & $70.43 \%$ & & $77.02 \%$ & $81.60 \%$ \\
\hline & Received measles vaccination & $57.78 \%$ & $76.83 \%$ & $65.47 \%$ & & $81.58 \%$ & $82.70 \%$ \\
\hline \multirow{4}{*}{ Curative } & ORS for diarrhea & $41.87 \%$ & $48.65 \%$ & $38.24 \%$ & & $55.08 \%$ & $45.90 \%$ \\
\hline & Antibiotics for diarrhea & & & & & $27.69 \%$ & \\
\hline & Search for pneumonia care & $38.54 \%$ & $55.36 \%$ & $59.07 \%$ & & $53.64 \%$ & $56.50 \%$ \\
\hline & Antimalarials - Artemisinin compounds for malaria & & $6.20 \%$ & $21.72 \%$ & & $22.52 \%$ & $35.60 \%$ \\
\hline
\end{tabular}

ITN/IRS - Insecticide-treated nets/indoor residual spraying, ORS - oral rehydrationn salts, DPT - diphtheria, pertussis and tetanus

* Disaggregated coverage values for breastfeeding, stunting, and wasting by age category are shown in Appendices S1 \& S2 in Online Supplementary Document. Provincial-level coverage values are also shown in Appendices S1 \& S2 in Online Supplementary Document. 


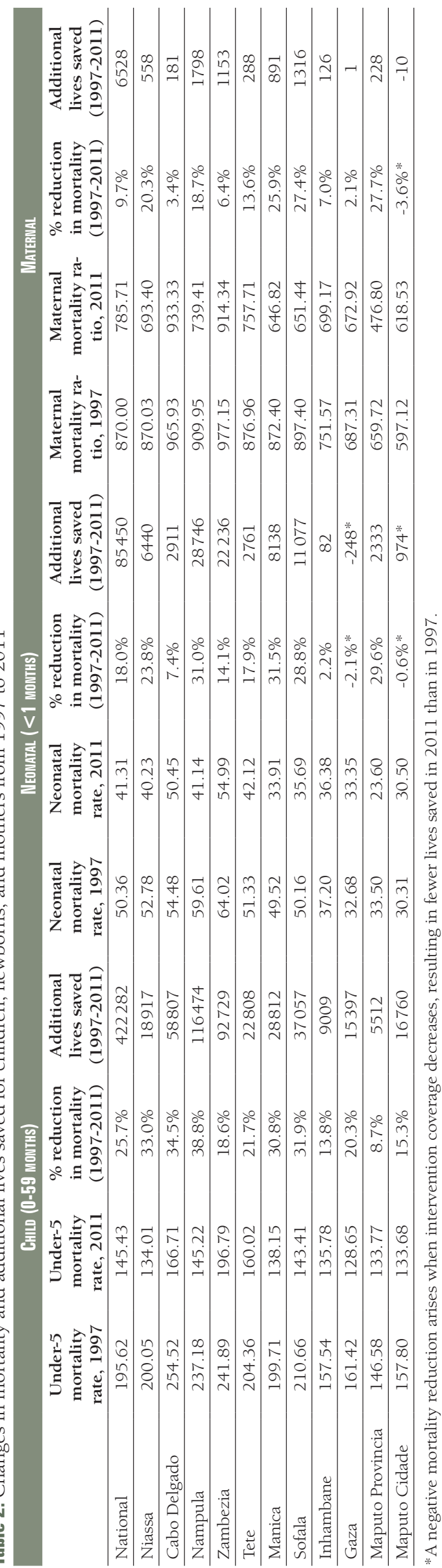

to City had low coverage of antimalarials in all years. Data from 1997 to 2015 showed consistent increases in coverage of maternal and neonatal interventions in 10 of the 11 provinces, with Manica showing decreasing coverage of antenatal care (ANC4), facility delivery, and skilled birth attendance from 2011 to 2015. All maternal interventions had higher coverage in the provinces from the southern region of Mozambique.

\section{Changes in mortality}

LiST estimates trends in mortality rates arising from changes in intervention coverage. Table 2 shows the mortality rates estimated by our projections. The national under-five mortality rate (U5MR) decreased from 196 in 1997 to 145 in 2011. The provinces in the northern region (Niassa, Cabo Delgado, Nampula) showed the greatest percentage reduction, while Maputo Province showed the smallest percentage reduction. The neonatal mortality rate (NMR) dropped from 50 in 1997 to 41 in 2011. Cabo Delgado was among the provinces with a high NMR in 1997 and its percentage reduction was only $7 \%$. Maputo Province already had a low NMR in 1997, but showed one of the greatest reductions in mortality from 1997 to 2011. Gaza and Maputo City showed slight increases in NMR from 1997 to 2011. The national maternal mortality ratio (MMR) decreased from 870 in 1997 to 786 in 2011 . Maputo Province showed the highest percentage reduction in MMR, while Maputo City showed a slight increase.

As mentioned in the introduction, we also have estimates of mortality from the DHS surveys in 1997, 2003, and 2011, which have been used by the UN Inter-agency Group for Child Mortality Estimation (UN IGME) to create an estimated trend of U5MR over time in Mozambique. This trend shows a more significant reduction in mortality over time than our modelled estimates, with a U5MR of 209 in 1997, 148 in 2003, and 95 in 2011 [10]. This stands to reason, since LiST only accounts for indicators that are inputted into the software. It is likely that other interventions, not inputted into our projections, also had an impact on mortality, resulting in a more significant reduction than suggested by our estimates.

\section{Causes of death}

Table 3 shows the proportion of deaths due to different causes in 1997 and 2011. In both years, malaria was the major cause of death among children under five, with approximately one in four deaths due to malaria. There was a decrease in the proportion of deaths due to measles, and an increase in the proportion of deaths caused by AIDS and wounds. Prematurity, asphyxia, and sepsis were the major causes of neonatal death in 1997 and 2011. From 1997 to 2011 the three major causes of maternal deaths were postpartum hemorrhage, other indirect causes of death, and antepartum hemorrhage. The major causes of death among children, neonates, and mothers at provincial level followed the same pattern as the causes of death at national level.

\section{Additional lives saved}

Our modelled estimates show that increases in intervention coverage from 1997 to 2011 saved an additional 422282 child lives (0-59 months), 85450 neonatal lives (0-1 month), and 6528 ma- 
Table 3. Top causes of death, in 1997 and 2011

\begin{tabular}{|c|c|c|c|}
\hline Cause of deAtH & 1997 & Cause of DeATH & 2011 \\
\hline \multicolumn{4}{|l|}{ Children (0-59 months): } \\
\hline Malaria & $26 \%$ & Malaria & $22 \%$ \\
\hline Diarrhea & $12 \%$ & Other & $13 \%$ \\
\hline Pneumonia & $12 \%$ & Pneumonia & $10 \%$ \\
\hline Other & $10 \%$ & Diarrhea & $10 \%$ \\
\hline Neonatal - Prematurity & $7.8 \%$ & Neonatal - Prematurity & $9.0 \%$ \\
\hline Neonatal - Asphyxia & $7.5 \%$ & Neonatal - Asphyxia & $7.3 \%$ \\
\hline Neonatal-Sepsis & $4.5 \%$ & AIDS & $6.2 \%$ \\
\hline Measles & $4.2 \%$ & Neonatal - Sepsis & $4.4 \%$ \\
\hline Meningitis & $4.0 \%$ & Wounds & $4.2 \%$ \\
\hline AIDS & $3.0 \%$ & Meningitis & $4.1 \%$ \\
\hline Wounds & $3.0 \%$ & Neonatal - Pneumonia & $2.4 \%$ \\
\hline Neonatal - Pneumonia & $2.3 \%$ & Measles & $2.2 \%$ \\
\hline Neonatal - Other & $1.4 \%$ & Neonatal - Other & $1.9 \%$ \\
\hline Neonatal - Congenital anomalies & $1.3 \%$ & Neonatal - Congenital anomalies & $1.8 \%$ \\
\hline Neonatal - Tetanus & $1.0 \%$ & Neonatal - Tetanus & $0.7 \%$ \\
\hline Whooping cough & $0.7 \%$ & Whooping cough & $0.6 \%$ \\
\hline Neonatal - Diarrhea & $0.3 \%$ & Neonatal - Diarrhea & $0.3 \%$ \\
\hline Total & $100 \%$ & Total & $100 \%$ \\
\hline \multicolumn{4}{|l|}{ Newborns (<1 months): } \\
\hline Neonatal - Prematurity & $30 \%$ & Neonatal - Prematurity & $32 \%$ \\
\hline Neonatal - Asphyxia & $29 \%$ & Neonatal - Asphyxia & $26 \%$ \\
\hline Neonatal - Sepsis & $17 \%$ & Neonatal - Sepsis & $16 \%$ \\
\hline Neonatal - Pneumonia & $8.7 \%$ & Neonatal - Pneumonia & $8.7 \%$ \\
\hline Neonatal - Other & $5.3 \%$ & Neonatal - Other & $6.7 \%$ \\
\hline Neonatal - Congenital anomalies & $5.2 \%$ & Neonatal - Congenital anomalies & $6.5 \%$ \\
\hline Neonatal - Tetanus & $3.9 \%$ & Neonatal - Tetanus & $2.5 \%$ \\
\hline Neonatal - Diarrhea & $1.0 \%$ & Neonatal - Diarrhea & $1.1 \%$ \\
\hline Total & $100 \%$ & Total & $100 \%$ \\
\hline \multicolumn{4}{|l|}{ Mothers: } \\
\hline Postpartum hemorrhage & $24 \%$ & Other indirect & $26 \%$ \\
\hline Other indirect & $22 \%$ & Postpartum hemorrhage & $20 \%$ \\
\hline Antepartum hemorrhage & $13 \%$ & Antepartum hemorrhage & $12 \%$ \\
\hline Sepsis & $11 \%$ & Sepsis & $11 \%$ \\
\hline Hypertensive diseases of pregnancy & $11 \%$ & Hypertensive diseases of pregnancy & $9.0 \%$ \\
\hline Other direct & $6.9 \%$ & Other direct & $8.3 \%$ \\
\hline Hypertensive diseases of pregnancy & $4.9 \%$ & Abortion & $6.1 \%$ \\
\hline Abortion & $4.7 \%$ & Obstructed labor & $4.4 \%$ \\
\hline Ectopic & $1.1 \%$ & Malaria & $1.6 \%$ \\
\hline Malaria & $1.0 \%$ & Ectopic & $1.3 \%$ \\
\hline Total & $100 \%$ & Total & $100 \%$ \\
\hline
\end{tabular}

\begin{abstract}
2015, increased coverage of neonatal in-
\end{abstract} terventions contributed 85450 and 11290 additional neonatal lives saved, respectively. Increased coverage of labor and delivery management (28\%), breastfeeding promotion (19\%), and full supportive care for neonatal sepsis/pneumonia (19\%) contributed the largest proportion of additional lives saved from 1997 to 2011. From 2011 to 2015, labor and delivery management continued to add the largest proportion of lives saved (29\%), with no data available for breastfeeding promotion and full supportive care for neonatal sepsis/pneumonia. Among the 6528 and 884 additional maternal lives saved for 1997-2011 and 2011-2015 respectively, the increased coverage of labor and delivery management contributed about half (58\%) and one third (31\%) of additional lives saved, respectively, followed by increased coverage of active management of the third stage of labor (AMTSL), magnesium-sulfate (MgSO4) for the management of eclampsia, and clean birth practices.

We have not presented our results of additional lives saved by intervention at provincial level, but these are available in Appendices S3-S5 in Online Supplementary Document. 
Table 4. Top 10 interventions for additional lives saved (1997-2015)

\begin{tabular}{|c|c|c|c|c|}
\hline \multirow{3}{*}{$\begin{array}{l}\text { INTERVENTION } \\
\text { Children (0-59 months): }\end{array}$} & \multicolumn{4}{|l|}{ National } \\
\hline & & & & \\
\hline & $\begin{array}{c}\text { Additional lives } \\
\text { saved (1997-2011) }\end{array}$ & $\begin{array}{c}\% \text { of lives saved } \\
(1997-2011)\end{array}$ & $\begin{array}{c}\text { Additional lives } \\
\text { saved (2011-2015) }\end{array}$ & $\begin{array}{c}\% \text { of lives saved } \\
(2011-2015)\end{array}$ \\
\hline Change in wasting prevalence & 82374 & $20 \%$ & \multicolumn{2}{|c|}{ Data not available for 2015} \\
\hline ITN/IRS & 55757 & $13 \%$ & \multicolumn{2}{|c|}{ Data not available for 2015} \\
\hline Artemisinin compounds (ACTs) for treatment of malaria & 34807 & $8 \%$ & 11920 & $41 \%$ \\
\hline Oral antibiotics for pneumonia & 29804 & $7 \%$ & & $4 \%$ \\
\hline Changes in breastfeeding & 27405 & $6 \%$ & \multicolumn{2}{|c|}{ Data not available for 2015} \\
\hline Measles vaccine & 26432 & $6 \%$ & 229 & $1 \%$ \\
\hline Labor and delivery management & 24041 & $6 \%$ & 3243 & $11 \%$ \\
\hline Change in stunting prevalence & 19257 & $5 \%$ & \multicolumn{2}{|c|}{ Data not available for 2015} \\
\hline Preventing mother to child transmission (PMTCT) & 19101 & $5 \%$ & 3621 & $13 \%$ \\
\hline Full supportive care, sepsis/pneumonia & 15928 & $4 \%$ & \multicolumn{2}{|c|}{ Data not available for 2015} \\
\hline Other & 87376 & $21 \%$ & 8580 & $30 \%$ \\
\hline Total & 422282 & $100 \%$ & 28742 & $100 \%$ \\
\hline \multicolumn{5}{|l|}{ Newborns ( $<$ l months): } \\
\hline Labor and delivery management & 24041 & $28 \%$ & 3243 & $29 \%$ \\
\hline Changes in breastfeeding & 16526 & $19 \%$ & \multicolumn{2}{|c|}{ Data not available for 2015} \\
\hline Full supportive care for neonatal sepsis/pneumonia & 15928 & $19 \%$ & \multicolumn{2}{|c|}{ Data not available for 2015} \\
\hline Tetanus toxoid vaccination & 7867 & $9 \%$ & \multicolumn{2}{|c|}{ Data not available for 2015} \\
\hline Neonatal resuscitation & 6335 & $7 \%$ & 1590 & $14 \%$ \\
\hline Clean birth practices & 3290 & $4 \%$ & 941 & $8 \%$ \\
\hline Thermal care & 3129 & $4 \%$ & 767 & $7 \%$ \\
\hline Immediate assessment and stimulation & 2909 & $3 \%$ & 950 & $8 \%$ \\
\hline Antibiotics for pPRoM & 2152 & $3 \%$ & 227 & $2 \%$ \\
\hline Oral antibiotics for neonatal sepsis/pneumonia & 1691 & $2 \%$ & \multicolumn{2}{|c|}{ Data not available for 2015} \\
\hline Other & 1582 & $2 \%$ & 3572 & $32 \%$ \\
\hline Total & 85450 & $100 \%$ & 11290 & $100 \%$ \\
\hline \multicolumn{5}{|l|}{ Mothers: } \\
\hline Labor and delivery management & 3118 & $48 \%$ & 275 & $31 \%$ \\
\hline Active management of the third stage of labor (AMTSL) & 1163 & $18 \%$ & 135 & $15 \%$ \\
\hline MgSO4 management of eclampsia & 801 & $12 \%$ & 93 & $11 \%$ \\
\hline Clean birth practices & 740 & $11 \%$ & 243 & $27 \%$ \\
\hline Antibiotics for pPRoM & 462 & $7 \%$ & 56 & $6 \%$ \\
\hline Tetanus toxoid vaccination & 97 & $1 \%$ & \multicolumn{2}{|c|}{ Data not available for 2015} \\
\hline Contraceptive use & 82 & $1 \%$ & \multicolumn{2}{|c|}{ Data not available for 2015} \\
\hline MgSO4 management of pre-eclampsia & 23 & $0 \%$ & 2 & $0 \%$ \\
\hline Hypertensive disorder case management & 21 & $0 \%$ & 3 & $0 \%$ \\
\hline Malaria case management & 11 & $0 \%$ & 0 & $0 \%$ \\
\hline Other & 10 & $0 \%$ & 77 & $9 \%$ \\
\hline Total & 6528 & $100 \%$ & 884 & $100 \%$ \\
\hline
\end{tabular}

ITN/IRS - Insecticide-treated nets/indoor residual spraying, ACTs - artemisinin compounds, pPRoM - preterm premature rupture of the membranes, AMTSL - active management of the third stage of labor, $\mathrm{MGSO}_{4}$ - magnesium sulfate

\section{DISCUSSION}

Since 1997, Mozambique has seen a considerable reduction in child mortality, reflecting the efforts made by the Ministry of Health to scale up proven child health interventions and roll out new interventions. Various vaccines were introduced over the past eight years (Pentavalent3/DPT3, pneumococcal and rotavirus); a national ITN household ownership strategy was rolled out in 2011; the implementation of pediatric ART and PMTCT was introduced in 2002 in Maputo and later in the remainder of the country; and a breastfeeding promotion strategy was begun in 2009 [14]. These efforts should be recognized and celebrated for their contributions to improving child health.

Our findings also offer details about the changes in coverage over 15 years (1997-2011) that contributed the most additional lives saved among children under five - in other words, the efforts that had the biggest impact. We found that wasting and malaria interventions were responsible for most of the addi- 
Table 5. Top 10 interventions for additional lives saved (2011-2015)

\begin{tabular}{|c|c|c|}
\hline \multirow[t]{2}{*}{ INTERVENTION } & \multicolumn{2}{|l|}{ National } \\
\hline & $\begin{array}{l}\text { Additional lives saved } \\
\text { (2011-2015) }\end{array}$ & $\%$ of lives saved \\
\hline \multicolumn{3}{|l|}{ Children (0-59 months): } \\
\hline Artemisinin compounds (ACTs) for treatment of malaria & 11920 & $41 \%$ \\
\hline PMTCT & 3621 & $13 \%$ \\
\hline Labor and delivery management & 3243 & $11 \%$ \\
\hline Injectable antibiotics for neonatal sepsis/pneumonia & 2977 & $10 \%$ \\
\hline Neonatal resuscitation & 1590 & $6 \%$ \\
\hline Oral antibiotics for pneumonia & 1149 & $4 \%$ \\
\hline Immediate assessment and stimulation & 950 & $3 \%$ \\
\hline Clean birth practices & 941 & $3 \%$ \\
\hline Thermal care & 767 & $3 \%$ \\
\hline Intermittent preventive treatment of malaria during pregnancy (IPTp) & 525 & $2 \%$ \\
\hline Other & 1059 & $4 \%$ \\
\hline Total & 28742 & $100 \%$ \\
\hline \multicolumn{3}{|l|}{ Newborns (<1 months): } \\
\hline Labor and delivery management & 3243 & $29 \%$ \\
\hline Injectable antibiotics for neonatal sepsis/pneumonia & 2977 & $26 \%$ \\
\hline Neonatal resuscitation & 1590 & $14 \%$ \\
\hline Immediate assessment and stimulation & 950 & $8 \%$ \\
\hline Clean birth practices & 941 & $8 \%$ \\
\hline Thermal care & 767 & $7 \%$ \\
\hline Intermittent preventive treatment of malaria during pregnancy (IPTp) & 525 & $5 \%$ \\
\hline Antibiotics for pPRoM & 227 & $2 \%$ \\
\hline Syphilis detection and treatment & 56 & $0 \%$ \\
\hline Preventing mother to child transmission (PMTCT) & 14 & $0 \%$ \\
\hline Other & 0 & $0 \%$ \\
\hline Total & 11290 & $100 \%$ \\
\hline \multicolumn{3}{|l|}{ Mothers: } \\
\hline Labor and delivery management & 275 & $31 \%$ \\
\hline Clean birth practices & 243 & $27 \%$ \\
\hline Active management of the third stage of labor (AMTSL) & 135 & $15 \%$ \\
\hline MgSO4 management of eclampsia & 93 & $11 \%$ \\
\hline Intermittent preventive treatment of malaria during pregnancy (IPTp) & 77 & $9 \%$ \\
\hline Antibiotics for pPRoM & 56 & $6 \%$ \\
\hline Hypertensive disorder case management & 3 & $0 \%$ \\
\hline $\mathrm{MgSO}_{4}$ management of pre-eclampsia & 2 & $0 \%$ \\
\hline Other & 0 & $0 \%$ \\
\hline Total & 884 & $100 \%$ \\
\hline
\end{tabular}

pPRoM - preterm premature rupture of the membranes, $\mathrm{MGSO}_{4}$ - magnesium sulfate

tional mortality reduction. However, we also found that malaria and malnutrition are still responsible for significant mortality in Mozambique, and thus continue to represent an opportunity to decrease child mortality further. In our analysis, more than one quarter of children were stunted in 2011, and malaria remains the biggest killer of children under five. A 2007 cause-of-death survey in Mozambique corroborates these findings, suggesting that malaria was responsible for $42.3 \%$ of under-five deaths [15]. These data highlight the importance and timeliness of recent further increases in government health financing to reduce under-five mortality [16].

Although increased coverage of interventions did reduce neonatal and maternal mortality in most provinces, the increase was not consistent and was limited in some areas, especially in Cabo Delgado, Gaza, and Maputo City. We found that interventions related to labor and delivery management averted more than half of the maternal deaths and more than one quarter of the neonatal deaths in the last 19 years. However, interventions related to prevention of maternal mortality such as antenatal care, skilled birth attendance, and institutional delivery showed lower coverage increases compared to other preventive and curative interventions, hence the smaller reduction in maternal mortality from 1997 to 2011 compared to child mortality. While there was an increase in coverage of facility delivery to more than $90 \%$ in Ma- 
puto Province in 2011, other provinces have yet to achieve such coverage of facility delivery or antenatal care. Additionally, only one fifth of pregnant women received preventive treatment for malaria in 2011 at national level. This may be due to a limited awareness of the consequences of malaria in pregnancy, especially for newborns [17].

The findings from this paper emphasize the success of the government in increasing coverage of existing interventions saving hundreds of thousands of additional lives, beyond those that were already being saved by existing coverage of interventions in 1997. This highlights the value of a multi-targeted approach, increasing awareness and uptake of new strategies, while further increasing access to and utilization of existing interventions. However, with all this in mind, more must be done not only to improve the coverage of interventions but also to improve the quality of such interventions, requiring more attention to policy implementation and health service delivery. Policy-makers should also ensure that gaps in intervention coverage are reduced not only in wealthy or urban areas of the country, but equitably across Mozambique. A multi-country analysis for low and middle income countries showed that both relative and absolute wealth-related and educational inequalities in maternal and neonatal health decreased in the last decade in Mozambique [18]. Nevertheless, in countries with low levels of antenatal care such as Mozambique, scaling up this service to rural and underserved areas might be an effective strategy to reduce health inequities.

\section{Limitations}

As a retrospective analysis of secondary data, we depended on the data available to us. We were only able to include indicators modelled in LiST and indicators for which we had reliable data. Specifically, due to the limited number of interventions in the 2015 IMASIDA survey data set, we could not reliably estimate trends in mortality or causes of death for 2011-2015, or compare additional lives saved in that period with the 1997-2011 period. As such, we were only able to report most results for 1997-2011. Data limitations during the 1997-2011 period also explain why the mortality trends generated by our LiST projections (Table 2) under-represent the decline in mortality reported in DHS surveys from 1997, 2003, and 2011. The mortality decline in our projections only captures the coverage changes for interventions that we could model.

While these limitations raise questions about our mortality rate calculations, they do not negate the value of our intervention-specific findings on additional lives saved. Even for the 2011-2015 period, our findings reflect accurately the additional lives saved attributable to those interventions for which we have data - the lack of data on other interventions does not affect our estimates for the interventions for which we do have data. Although LiST does not allow users to produce confidence intervals for uncertain coverage estimates, this paper nonetheless offers important estimates for the relative impact of interventions, an output that can help to define priority interventions in the future. This analysis also highlights the value of using existing survey data to understand the health landscape in Mozambique, especially as routine health information system (HIS) data on mortality and causes of death are still lacking at both national and provincial levels.

\section{CONCLUSION}

The findings from our analysis and previous surveys of mortality show that Mozambique has made great strides towards achieving MDG 4. Efforts to achieve MDG 5 have been less fruitful. Mozambique should continue striving to reduce child, neonatal, and maternal mortality - to achieve the SDGs by 2030, but more importantly to improve the lives of women and children across the country. Further commitments to interventions that we know save lives, such as ITN/IRS and improved labor and delivery management, should be sought, and additional effort should be made to monitor the impact of interventions on child and maternal health. More lives can be saved by continuing to increase coverage of existing health interventions and exploring new ways to reach underserved populations. 


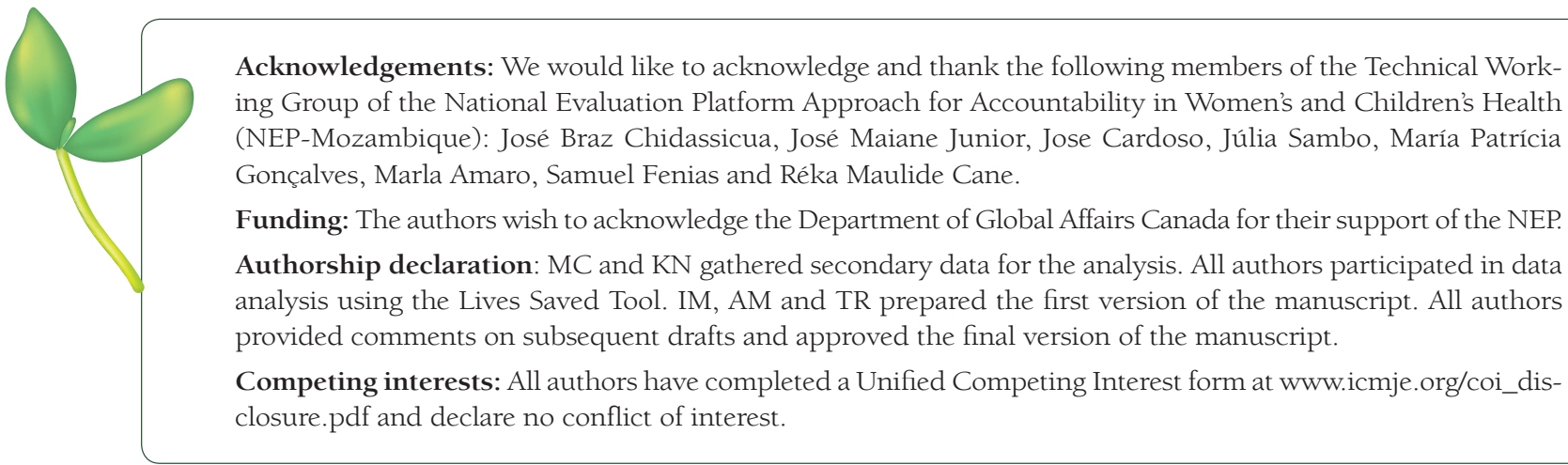

1 United Nations Foundation. What We Do: The Millennium Development Goals [Internet]. 2012. Available: http://www. unfoundation.org/what-we-do/issues/mdgs.html. Accessed 08 May 2017.

2 Instituto Nacional de Estatistica. Moçambique Inquérito Demográfico e de Saúde 1997 [Internet]. 1998 Sept. Available: http://www.ine.gov.mz/operacoes-estatisticas/inqueritos/inquerito-demografico-e-de-saude/ids-1997.pdf/view. Accessed 08 May 2017.

3 Instituto Nacional de Estatistica. Moçambique Inquerito Demografico e de Saúde 2003 [Internet]. 2005 Jun. Available: http://www.ine.gov.mz/operacoes-estatisticas/inqueritos/inquerito-demografico-e-de-saude/ids-2003.pdf/view. Accessed 08 May 2017.

4 Instituto Nacional de Estatistica. Moçambique - Inquerito Demografico e de Saúde, Demographic Health Surveys (DHS) - Visăo global [Internet]. 2011. Available: http://mozdata.microdatahub.com/index.php/catalog/15/study-description. Accessed 08 May 2017.

5 República de Moçambique Ministério da Saúde. Plano Estratégico do Sector da Sade 2014-2019. Maputo; 2013.

6 Walker N, Tam Y, Friberg IK. Overview of the Lives Saved Tool (LiST). BMC Public Health. 2013;13 Suppl 3:S1. Medline:24564438 doi:10.1186/1471-2458-13-S3-S1

7 Stegmuller AR, Self A, Litvin K, Roberton T. How is the Lives Saved Tool (LiST) used in the global health community? Results of a mixed-methods LiST user study. BMC Public Health. 2017;17:773. Medline:29143640 doi:10.1186/ s12889-017-4750-5

8 Winfrey W, McKinnon R, Stover J. Methods used in the Lives Saved Tool (LiST). BMC Public Health. 2011;11:S32. Medline:21501451 doi:10.1186/1471-2458-11-S3-S32

9 Amouzou A, Kanyuka M, Hazel E, Heidkamp R, Marsh A, Mleme T, et al. Independent Evaluation of the integrated Community Case Management of Childhood Illness Strategy in Malawi Using a National Evaluation Platform Design. Am J Trop Med Hyg. 2016;94:574-83. Medline:26787158 doi:10.4269/ajtmh.15-0584

10 United Nations Inter-agency Group for Child Mortality Estimation (UN IGME). Levels \& Trends in Child Mortality: Report 2017, Estimates Developed by the UN Inter-agency Group for Child Mortality Estimation. 2017. United Nations Children's Fund, New York. 2017.

11 Trends in maternal mortality: 1990 to 2015. Estimates by WHO, UNICEF, UNFPA, World Bank Group and the United Nations Population Division. 2015. Available from: http://www.who.int/reproductivehealth/publications/monitoring/ maternal-mortality-2015/en/. Accessed 08 May 2018.

12 Liu L, Oza S, Hogan D, Chu Y, Perin J, Zhu J, et al. Global, regional, and national causes of under-5 mortality in 200015: an updated systematic analysis with implications for the Sustainable Development Goals. Lancet. 2016;388:302735. Medline:27839855 doi:10.1016/S0140-6736(16)31593-8

13 Say L, Chou D, Gemmill A, Tunçalp Ö, Moller AB, Daniels J, et al. Global causes of maternal death: a WHO systematic analysis. Lancet Glob Health. 2014;2:e323-33. Medline:25103301 doi:10.1016/S2214-109X(14)70227-X

14 República de Moçambique. Aprofundamento para o Relatório de Avaliaçăo do Impacto PARPA II (2006-2009): Área de Nutriçăo. 2009.

15 Instituto Nacional de Estatística. Inquérito Nacional sobre Causas de Mortalidade 2007/8 [Internet]. 2009. Available: http://www.ine.gov.mz/operacoes-estatisticas/inqueritos/inquerito-sobre-causas-de-mortalidade/inquerito-nacional-sobre-causas-de-mortalidade-2007-8.pdf/view. Accessed 08 May 2018.

16 Fernandes QF, Wagenaar BH, Anselmi L, Pfeiffer J, Gloyd S, Sherr K. Effects of health-system strengthening on under-5, infant, and neonatal mortality: 11-year provincial-level time-series analyses in Mozambique. Lancet Glob Health. 2014;2:e468-77. Medline:25103520 doi:10.1016/S2214-109X(14)70276-1

17 Diala CC, Pennas T, Marin C, Belay KA. Perceptions of intermittent preventive treatment of malaria in pregnancy (IPTp) and barriers to adherence in Nasarawa and Cross River States in Nigeria. Malar J. 2013;12:342. Medline:24059757 doi:10.1186/1475-2875-12-342

18 McKinnon B, Harper S, Kaufman JS, Yves Bergevin Y. Socioeconomic inequality in neonatal mortality in countries of low and middle income: a multicountry analysis. Lancet Glob Health. 2014;2:e165-73. Medline:25102849 doi:10.1016/ S2214-109X(14)70008-7 